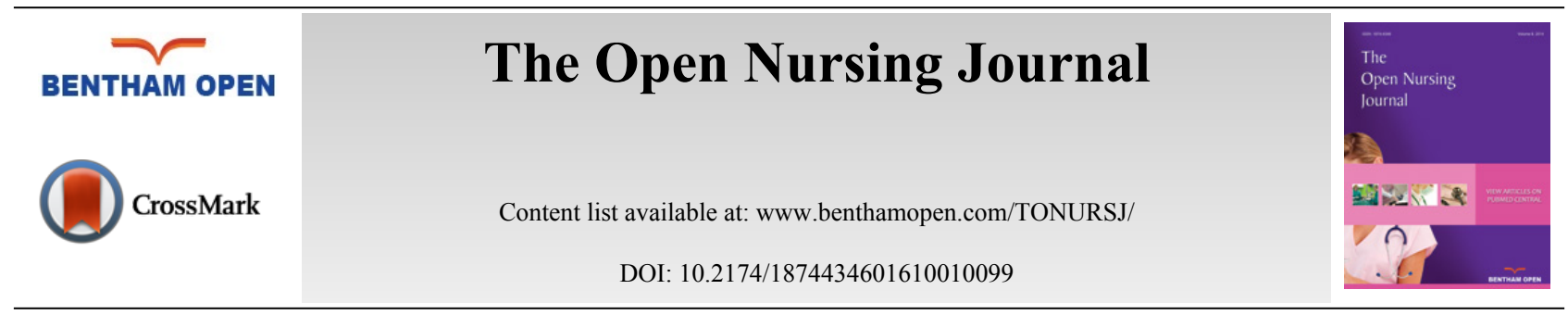

\title{
An Investigation of Nurses' Job Satisfaction in a Private Hospital and Its Correlates
}

\author{
Wai-Tong Chien ${ }^{*}$ and Sin-Yin Yick \\ School of Nursing Faculty of Health and Social Sciences, The Hong Kong Polytechnic University Hung Hom, Kowloon \\ Hong Kong SAR
}

Received: November 11, 2015

Revised: February 16, 2016

Accepted: February 20, 2016

\begin{abstract}
:
Background:

Nurses' job satisfaction and job stress are important issues regarding their turnovers. While there are some recent descriptive studies on job satisfaction in public hospitals, very limited research was found on this topic in private hospital setting. It is worth to examine the job satisfaction of nurses and its correlates in such a specific hospital context in Hong Kong, by which the findings can be compared with those in public hospitals, and across countries.
\end{abstract}

Aims:

To investigate nurses' job satisfaction, job stress and intention to quit of nurses in a private hospital, and the correlates of the nurses' job satisfaction.

\section{Design:}

A cross-sectional, descriptive survey study was conducted.

\section{Methods:}

By using stratified random sampling in terms of nature of wards/units and working ranks, 139 full-time nurses who were working in the 400-bed private hospital for at least 6 months and provided direct nursing care were recruited in this study. Data were collected by employing a set of self-administered structured questionnaires, consisting of the Index of Work Satisfaction (job satisfaction), Anxiety-Stress Questionnaire (job stress), Michigan Organizational Assessment Questionnaire (intention to quit), and sociodemographic data.

\section{Results:}

With a response rate of $74.3 \%$, the results of the 139 respondents showed that the nurses in the private hospital had an overall moderate level of satisfaction with their work and rated the professional status as the highest satisfied domain. The nurses also reported moderate levels of job stress and intention to quit. The nurses' job satisfaction was negatively correlated with their job stress and intention to quit; whereas, the nurses' job stress was positively correlated with their intention to quit. The nurses with older in age and more post-registration experience and/or working experience in the private hospital indicated a higher level of job satisfaction, particularly with 'Pay' and 'Autonomy'.

\section{Conclusion:}

The findings suggest that the nurses in the private hospital are moderately stressful and satisfied with their work environment and relationships. A few socio-demographic characteristics of these nurses such as their age and years of clinical experiences were associated with their levels of job satisfaction and/or stress. The findings provided information for private hospitals and healthcare

\footnotetext{
* Address correspondence to this author at the School of Nursing Faculty of Health and Social Sciences, The Hong Kong Polytechnic University Hung Hom, Kowloon Hong Kong SAR; Tel: (852) 2766 5648; Email: wai.tong.chien@polyu.edu.hk
} 
organizations about the need and areas for improvement of nurse's job satisfaction, thus strengthening their recruitment and retention.

Keywords: Cross-sectional survey, Intention to quit, Job satisfaction, Job stress, Private hospital.

\section{INTRODUCTION}

Job satisfaction among health professionals is a topic of global interest for a long time [1]. The topic persists to be important because it affects the employees' (professionals') job performance and subsequently quality of hospital and healthcare services $[1,2]$. Job satisfaction and job stress are highlighted by nurses, for which job satisfaction is significant negatively correlated to stress and intention to leave employment and affecting the turnover within the nursing profession [3]. The main reasons for affecting job satisfaction, as frequently cited in literatures, are heavy workload and poor peer support [4]. Studies have also showed that the effects of poor organizational climate, autonomy and salary are factors related to the consequence of nurses' job satisfaction [5,6]. Factors affecting job satisfaction, as frequently cited in nursing literature, are heavy workload, poor conditions in peer support, organizational climate, autonomy, and salary [4 - 6], in which all may ultimately lead to high staff turnovers.

In Hong Kong, nursing profession is a highly valued career for its high salary and job security [4]. However, nursing shortage and increased turnover rate have perplexed for decades globally, as well as in Hong Kong [6, 7]. According to the Hong Kong's Information Services Department, there were 1,721 nurses left the public healthcare services in $2008 / 09$. The turnover rates were $4.5 \%$ and $4.7 \%$ with respect to the two fiscal years, both values are slightly higher than the average nurse turnover rate of about $3 \%$ in the past decade. In compensation to that turnover, 1,545 nurses were recruited in 2009 [8]. The high turnover rate could be attributed by nurses' job moving or swapping between public hospitals, private hospitals and with other healthcare organizations, or even entirely leaving the nursing field. Overtly, there has been an increasing trend of turnover; and nursing shortage would even be more serious in foreseeable future. Nevertheless, Hong Kong has recently not been any research regarding nurses' job satisfaction and its related issues, particularly in private hospital setting that are often omitted due to its unique culture, practices and environment. It is interesting to be further studying on this topic area, and hoping that the results could provide more evidence for the policymakers to re-establish a satisfactory environment for nurses, and/or other clinicians, and thus developing a high level of job satisfaction among the hospital employees.

\section{Importance of Job Satisfaction in Nurses}

Job satisfaction is the extent to which an employee likes or enjoys his/her jobs [9 - 11]. It can be referred to the individual's general attitude or perceptions towards his/her work [1, $11-14]$. The level of job satisfaction can be based on the level of importance that an employee has placed on the rewards and/or benefits in their employment. Employees will be more satisfied with their job if it provides a reward that is very important for them [12]. An employee shows a pleasant emotional state resulted from the benefits of his/her job [5] and have greater job satisfaction. Therefore, nurses' job satisfaction is one of the important staff-concerning issues in recruiting and maintaining nursing manpower in hospitals $[7,15]$.

Nursing manpower shortage is a global problem that influences the accessibility of health care services, the quality of patient care and the overall resource management of healthcare system $[11,16]$. Nurses' job satisfaction is a crucial factor to understand the impact of continuing nursing shortage [17]. In 2000, the Advisory Board Company Nursing Executive Center examined the relationship between job satisfaction and intention to leave; and its report suggested that over half of the nurses who had reduction of job satisfaction in the first two years planned to leave their organization and nearly half of them did not have long-term commitment in their current position. This negative attitude of nurses towards their work would increase the nurses' intention to quit, which can be considered the 'push' factors on their turnover rate.

In addition, a high level of nurses' job stress is associated with their poor job satisfaction, increasing absenteeism, turnover and nursing shortage $[12,18,19]$, and further increasing the productivity cost and instability and lowering the quality of care in healthcare organization involved [18].

Siu [4] and Gruss [20] indicated job satisfaction is an important predictor on absenteeism. It interrupts schedule, creates a need for over-staffing, and raises an organizational costs; absenteeism is also highly correlated with turnover as the final decision [4]. Of which, turnover is even more costly as the result of recruiting and training replacement employees. Therefore, job satisfaction is a main 'pull' factors against the nurses' turnover [2, 21 - 23]. Nurses who are 
more satisfied with their job environment, benefits and situation are less likely to leave the workplace [12, 17, 23]. It is important to conduct further study on the relationship between job satisfaction and turnover of nurses in different developed countries such as Hong Kong.

\section{Factors Influencing Nurses' Job Satisfaction}

Job satisfaction is crucially important in the nursing field where team spirit and cooperation between team members are key elements in providing quality and continuous patient care. Studies showed that job satisfaction would enhance the establishment of optimistic attitude, which creates the rapport between nursing staff, increases their peer interactions and between nurses and patients, and enhances confidence of individual nurses [6, 24]. Subsequently, job satisfaction can improve teamwork and thus increase patient satisfaction with care by collaborative and partnered patient care [5, 7]. However, sources of job satisfaction vary across different settings and countries, which are worth to be investigated and compared.

Researchers have attempted to identify the components of job satisfaction; and several factors such as interpersonal relationship and communication, professionalism and career development, organization policy, autonomy, and pay are commonly found $[5,14,25,26]$. Most studies reported positive relationship between nurses' job satisfaction with pay and benefit $[25,27,28]$. Besides, Studies have also revealed the importance of professionalism, and professional development for job satisfaction [18, 25]. Bratt et al. [29] also pointed out the opportunities for promotion would have great impact on satisfaction. A Chinese study also found that nurse were less satisfied because of the decrease career advancement opportunity and promotion where emphasizes on critical thinking and decision making [30]. However, Tzeng [31] conducted a study in Taiwan Chinese people did not agree salary and promotion have strong relationship with job satisfaction as nurses' reported that they have less control on it.

Job related stress has been considered as an important element on job satisfaction. Studies have identified the sources of stress in nurse as workload, leadership or management improficiency, professional conflicts and emotional demands of caring [32]. Bratt, et al. [29] studied the influence of stress and nursing leadership on job satisfaction in a sample of 1973 pediatric nurses in intensive care units. The results showed that there was a significant negative correlation between job stress and job satisfaction of these nurses. The stress received by nurses would decrease the job satisfaction affecting their performance, contributing to inefficient labor market would be considered a 'push' factor towards turnovers. Thereby, several studies supported that reducing the workload would lessen the job stress, resulting in an increase of job satisfaction [25, 29].

Other associated factors, including individual predisposing characteristics such as age, years of experience and education level are found to have associations or impacts on nurses' job satisfaction. A study suggested that younger and higher educated nurses are more likely to have less satisfaction with their jobs than older and less educated nurses, because well educated nurses have higher expectation towards their job [5]. However, there are contradictory results showed in a cross-sectional study using 1,973 staff nurses, and found that the degree of nurse job satisfaction did not differ across age groups, education levels or years of clinical experience [29]. For gender, Siu [4] showed that male nurses were less satisfied with their job than the female nurses [4], while McGilton et al. [33] indicated lower levels of job satisfaction are more common in females due to higher job-related stress and less collegial support received. Differences on environmental (external), situational/interactional, and personal (internal) factors influencing job satisfaction can be resulted from the socio-ethnic, cultural and contextual variations across settings.

While there are a few instruments measuring job satisfaction, the Index of Work Satisfaction (IWS) and McCloskey/ Mueller Satisfaction Scale (MMSS) are more frequently used. The IWS is frequently successfully adapted in measuring nurses' job satisfaction for 25 years because this scale was developed with nurses in healthcare settings and has shown very satisfactory reliability and validity in Western and Asian countries [5,34]. In addition, intention to quit of nurses can be measured with a simple and user-friendly questionnaire, the Michigan Organizational Assessment Questionnaire, rated on a 5-point Likert scale and demonstrated adequate reliability (i.e., Cronbach's alpha of 0.70) [35, 36].

\footnotetext{
Aims

To fill in the knowledge gap of better understanding job satisfaction and its related factors in hospital settings, this study was to investigate the correlates of job satisfaction of nurses in a regional private hospital of Hong Kong. The objectives of this study were: (1) to investigate the levels of job satisfaction, job stress and intention to quit of nurses in the hospital; (2) to examine the relationships between job satisfaction, job stress and intention to quit; and, (3) to examine the relationships between nurses' job satisfaction and their socio-demographic characteristics.
} 


\section{METHODS}

\section{Study Design and Participants}

A cross-sectional, descriptive survey was conducted in one of five private hospitals, which was randomly selected from a hospital list, providing very comprehensive hospital care services in Hong Kong. Data were collected by selfcompletion of a set of structured questionnaires due to low cost and time effective in accessing a large sample, high flexibility for researcher to access and collect data in the study venue, ensuring anonymity, and free of researcher bias $[37,38]$.

Based on the staff records between January and February 201, about 650 potential subjects (nurses) were selected from the private hospital. These nurses should meet the inclusion criteria that they were those who were: (a) employed full time in providing direct care to their patients, including ward managers, senior nurses, registered nurses, and enrolled nurses, and (b) working in the hospital for at least six months. However, nurse officers and administrators, part-time nurses, and those with less than 6 months of working experience in the hospital were excluded from this study. There were 578 nurses found eligible for this study and 187 nurses $(28 \%)$ were selected by stratified random sampling according to their nature of ward or working setting and working ranks, which could ensure equal proportion and better representation of different work nature and seniority of nurses to be selected, thus reducing the selection bias [39]. This sample size could also detect a medium level of correlation (0.3) at a power of $0.80, p$ value of 0.05 [40], taking into account of $10 \%$ of incompletion and refusal rate. Therefore, 99 nurses from acute care, 59 from rehabilitation and outpatient care, and 29 from first-class private wards were selected.

\section{Instruments}

Instruments used in the study were the Index of Work Satisfaction (IWS), Anxiety Stress Questionnaire (ASQ), Michigan Organizational Assessment Questionnaire (MOAQ) - Intention to Turn Over, and a demographic data sheet designed by the researchers.

The IWS developed by Stamps and Piedmont [41] was widely used for measurement of the level of nurses' job satisfaction. The second section of the IWS consisting of 44 items of satisfaction survey was used in this study; whereas, the first section about socio-demographic characteristics might not be appropriate to local setting and thus not to be adopted in this study. There were six domains in the second section, including pay, autonomy, task requirements, organizational policy, interaction, and professional status. Participants responded to the items on a 7-point Likert scale from ' 1 - strongly disagree' to '7 - strongly agree'; the higher the mean score, the higher the respondent's level of job satisfaction. Internal consistency of IWS was good with Cronbach's alpha coefficients ranged from 0.82 to 0.91 for the six subscales and 0.90 for the overall scale [10].

The ASQ developed by House and Rizzo [42] consisted of 17 items and measured the job-induced tensions and pressures of employees in different work settings. The items were categorized into three subscales, including jobinduced tension (JIT), somatic tension (ST), and general fatigue and uneasiness (GFU). Responses to each item would be ' $2=$ true' or ' $1=$ false', except items 1 and 2 (which were reversed in scoring). A higher score would represent a higher degree of stress level in overall scale and subscales. The internal consistency of the ASQ was good (i.e., Cronbach's alpha coefficients were $0.72-0.83$ for the subscales and 0.76 for the overall scale) and its test-retest reliability was satisfactory $(\mathrm{r}=0.79)$. The scale has been widely used across nursing and industrial settings in Hong Kong and other developed countries.

The MOAQ developed by Cammann et al. [44] measured valid outcome of turnover intention. It was a 3-item scale to measure the staff's intention of leaving their current position and the probability of seeking another position in the coming six months. Items were rated on a 7-point Likert scale, ranging from '1-unlikely' to '7-very likely'. It shows a satisfactory reliability with a Cronbach's alpha coefficient of 0.70 [36] .

Socio-demographic data were collected using a researcher-designed data sheet, consisting of items for age, gender, marital status, number of children, education level, years of nursing experience, rank or grade of working position, salary, and working unit/ward.

\section{Data Collection}

With the permission of nursing director of the hospital, each participant was given a set of questionnaires (IWS, ASQ and MOAQ), a demographic data sheet and an opaque envelope with an invitation letter of the study (containing 
the purpose, procedure and significance of the study). The questionnaires were distributed to the selected nurses by a research assistant individually at the beginning of their duty shift. Participants were asked for agreement and signing for consent as well as a return of the anonymous questionnaires enclosed in the sealed envelope to the researchers into a collection box in the nurses' station. They were also reminded of completion of all items and checking against their completion before putting the questionnaires into the envelope. Reminders were sent via hospital internal mails to all of these 187 selected nurses two weeks after distribution of the questionnaires. Turnover rate of the nurses was obtained from the hospital staff records six months afterwards.

\section{Ethical Considerations}

Ethical approvals were obtained from the Human Subjects Research Ethics Committee of The Hong Kong Polytechnic University and the private hospital under study. Confidentiality and anonymity were assured to the participants and they were informed of the right of withdrawal from the study at any time without any negative consequence on their employment. Implied consent was made if they were willing to complete and return the questionnaires to the researchers.

\section{Data Analysis}

The IBM's Statistical Package for the Social Sciences (SPSS) for Windows, version 18.0 was used to analyze data. Descriptive statistics was used to summarize the level of job satisfaction, job stress, demographic and job-related characteristics of the nurses. Pearson's correlation was used to examine the relationship between job satisfaction, job stress, intention to quit and demographic data in internal data such as age. Spearman' Rho test was used to examine the correlation between job satisfaction, job stress, and nurses' socio-demographic characteristics such as education level (in ordinal level) without any violation of homogenestiy of varicene $(p>0.05)$ noted among the data. One-way analysis of Variance (ANOVA) test was used to compare the differences on levels of job satisfaction and/or job stress between subgroups in terms of their demographic characteristics, if they were found correlated. The significant level of all statistical tests was set at 0.05 .

The actual turnover rate of the participants at a six-month interval after the two months' returns (March and April 2014) of the study questionnaires were obtained from the staff employment of the hospital.

\section{RESULTS}

A total of 187 questionnaires were sent out and 140 questionnaires were completed and returned (i.e., the response rate was $74.3 \%$ ). Finally, 139 questionnaires were used for data analysis; one questionnaire was discarded due to excessive missing data ( $>5 \%$ of items in either the overall set of questionnaires or one scale). The final respondents represented $21 \%$ of the total target population of nurses in the private hospital under study.

\section{Socio-Demographic Characteristics of Nurses}

Majority of the nurses were female $(\mathrm{n}=120,86 \%)$. About $87 \%$ were registered and enrolled nurses $(\mathrm{n}=66$ and 55 , respectively). Most of the nurses were aged between 21-30 years (58.1\%), single (56.8\%), and had no child (69.0\%). Half of them had baccalaureate degree (49.6\%) and only $22.6 \%$ had diploma level of education. Their length of job experience in the private hospital ranged between 0.5 and 5 years $(60.7 \%)$. Majority of them were working in acute $(n=95,68 \%)$ and outpatient care $(n=38,27 \%)$ setting. The socio-demographic characteristics of the nurse respondents are summarized in (Table 1).

Table 1. Socio-demographic data of the respondents $(\mathrm{N}=139)$.

\begin{tabular}{|c|c|}
\hline Characteristic & Frequency (\%) \\
\hline Age $(\mathrm{n}=124$, mean=32.69, $\mathrm{SD}=9.62)$ & $72(58.1 \%)$ \\
$21-30$ years old & $26(21.0 \%)$ \\
$31-40$ years old & $20(16.1 \%)$ \\
$41-50$ years old & $6(4.8 \%)$ \\
$51-60$ years old & $120(86.3 \%)$ \\
\hline Gender & $19(13.7 \%)$ \\
\hline Female & \\
\hline
\end{tabular}




\begin{tabular}{|c|c|}
\hline Characteristic & Frequency (\%) \\
\hline $\begin{array}{c}\text { Marital status } \\
\text { Single } \\
\text { Married } \\
\text { Divorced }\end{array}$ & $\begin{array}{c}79(56.8 \%) \\
59(42.4 \%) \\
1(0.7 \%)\end{array}$ \\
\hline $\begin{array}{l}\text { Number of child }(\mathrm{n}=116) \\
\text { no child } \\
1-2 \text { children } \\
3-4 \text { children }\end{array}$ & $\begin{array}{c}80(69 \%) \\
34(29.3 \%) \\
2(1.7 \%)\end{array}$ \\
\hline $\begin{array}{c}\text { Shift of duty }(\mathrm{n}=134) \\
\text { Shift duty } \\
\text { Regular duty } \\
\text { Others (e.g., permanent night duty) }\end{array}$ & $\begin{array}{c}51(38.0 \%) \\
71(53 \%) \\
12(9.0 \%)\end{array}$ \\
\hline $\begin{array}{l}\text { Working hour }(\mathrm{n}=138) \\
8 \text { hours } \\
10 \text { hours } \\
12 \text { hours } \\
\text { Others }\end{array}$ & $\begin{array}{c}95(68.8 \%) \\
30(21.8 \%) \\
1(0.7 \%) \\
12(8.7 \%)\end{array}$ \\
\hline $\begin{array}{l}\text { Post registration experience (years) } \\
\qquad \begin{array}{c}(\mathrm{n}=135, \text { mean }=10.04, \mathrm{SD}=9.62) \\
<5 \text { years } \\
5-10 \text { years } \\
>10 \text { years }\end{array}\end{array}$ & $\begin{array}{l}68(50.4 \%) \\
21(15.6 \%) \\
46(34.1 \%)\end{array}$ \\
\hline $\begin{array}{l}\text { Experience in the private hospital (years) } \\
\qquad \begin{array}{c}(\mathrm{n}=135, \text { mean }=8.19, \mathrm{SD}=8.73) \\
<5 \text { years } \\
5-10 \text { years } \\
>10 \text { years }\end{array}\end{array}$ & $\begin{array}{l}82(60.7 \%) \\
16(11.9 \%) \\
37(27.4 \%)\end{array}$ \\
\hline $\begin{array}{l}\text { Highest nursing qualification }(\mathrm{n}=133) \\
\text { Diploma } \\
\text { Higher Diploma } \\
\text { Baccalaureate } \\
\text { Master }\end{array}$ & $\begin{array}{c}30(22.6 \%) \\
28(21.0 \%) \\
66(49.6 \%) \\
9(6.8 \%)\end{array}$ \\
\hline $\begin{array}{c}\text { Workplace } \\
\text { Medical and surgical wards } \\
\text { Outpatient clinic and Day centre } \\
\text { Operation theatre } \\
\text { Intensive care unit }\end{array}$ & $\begin{array}{c}71(51.1 \%) \\
36(25.9 \%) \\
23(16.5 \%) \\
9(6.5 \%)\end{array}$ \\
\hline $\begin{array}{c}\text { Rank } \\
\text { Enrolled nurse } \\
\text { Registered nurse } \\
\text { Senior registered nurse ( }>8 \text { years of experience) } \\
\text { Ward manager }\end{array}$ & $\begin{array}{c}55(39.6 \%) \\
66(47.4 \%) \\
10(7.2 \%) \\
8(5.8 \%)\end{array}$ \\
\hline $\begin{array}{c}\text { Salary }(\text { HKD }) \#(n=137) \\
\text { Below } 20,000 \\
20,000-29,999 \\
30,000-39,999 \\
40,000 \text { or above }\end{array}$ & $\begin{array}{l}42(30.7 \%) \\
21(15.3 \%) \\
28(20.4 \%) \\
46(33.6 \%)\end{array}$ \\
\hline
\end{tabular}

Note: \# US\$1 = HKD7.8

\section{Job Satisfaction, Job Stress and Intention to Quit}

Means and standard deviations of the IWS (job satisfaction) and ASQ (job stress) are summarized in Table 2. The mean total scores of the IWS and ASQ were 3.81 ( $\mathrm{SD}=0.37$; possible score range 1-7) and 24.04 ( $\mathrm{SD}=3.74$; possible score range $=16-32$ ), respectively, indicating a moderate level of overall job satisfaction in the nurses and a below normative ASQ score of 33.23 ( $\mathrm{SD}=5.0$ ) reported in Cook et al.'s (1981) study. Among the subscales, 'Professional status' (mean=4.52, $\mathrm{SD}=0.68$ ) in the IWS and 'Job-induced tension' (mean=11.22, SD=2.11) in the ASQ were reported to be the highest mean scores. Whereas, the lowest mean score among the IWS subscales was found in 'Task requirement' (mean $=3.07, \mathrm{SD}=0.73$ ).

Table 2. Means and standard deviations of IWS $(\mathrm{N}=139)$.

\begin{tabular}{|c|c|c|}
\hline Instrument & Mean \\
\hline IWS (1-7) & $3.81 \#$ & 0.37 \\
\hline Professional status $(1-7)$ & $4.52 \#$ & 0.68 \\
\hline
\end{tabular}




\begin{tabular}{|c|c|c|}
\hline Instrument & Mean & SD \\
\hline Pay (1-7) & $4.27 \#$ & 0.71 \\
\hline Autonomy (1-7) & $3.95 \#$ & 0.66 \\
\hline Organizational policy (1-7) & $3.83 \#$ & 0.71 \\
\hline Interaction (1-7) & $3.34 \#$ & 0.43 \\
\hline Task requirement (1-7) & $3.07 \#$ & 0.73 \\
\hline ASQ (16-32) & 24.04 & 3.74 \\
\hline$J I T(7-14)$ & 11.22 & 2.11 \\
\hline$S T(5-10)$ & 6.93 & 1.46 \\
\hline$G F U(4-8)$ & 5.89 & 1.00 \\
\hline
\end{tabular}

Note: IWS, Index of satisfaction scale; ASQ; Anxiety stress questionnaire. JIT, Job-induced tension; ST, Somatic tension; GFU, General fatigue and uneasiness.

$\wedge$ Possible range of the overall scale and subscales in the parentheses.

\# Mean score per item, indicating the total score of all respondents divided by multiplication value of the total numbers of both the respondents and items.

Looking into the item scores of the ASQ, about $70 \%$ of the nurses reported that they "worked under a great deal of tension" and "had trouble getting to sleep or staying asleep"; and 64\% reported "their job directly affected their health". The MQAQ (intention to quit) results indicated that the average score of intention to quit among the nurses was 3.22 ( $\mathrm{SD}=1.39$; possible score range 1-7), indicating these a moderate level of desire to leave the hospital. However, the actual turnover rate of the nurses over a six-month follow-up was $2.7 \%$, as shown in the records of the hospital's human resources office.

\section{Job Stress and Intention to Quit Related to Job Satisfaction}

Table 3 shows the results of Pearson's correlation test between the mean scores of the IWS (job satisfaction) and its subscales, the ASQ (job stress) and its subscales, and the MOAQ (intention to quit). Overall, job satisfaction of these nurses was found negatively correlated with job stress and intention to quit (both $\mathrm{p}=0.01$ ). In addition, the IWS mean score was negatively correlated with all three ASQ subscales (JIT: $r=-0.392, p=0.01 ; \mathrm{ST}: \mathrm{r}=-0.338, \mathrm{p}=0.01$; GFU: $r=$ $-0.207, \mathrm{p}=0.05$ ); whereas, the MOAQ (intention to quit) mean score was positively correlated with the three ASQ (job stress) subscales (JIT: $r=0.405, \mathrm{p}=0.01$; ST: $r=0.386, \mathrm{p}=0.01$; GFU: $\mathrm{r}=0.200, \mathrm{p}=0.05$ ).

Table 3. Correlation of job satisfaction with job stress and intention to quit $(n=139)$.

\begin{tabular}{|c|c|c|}
\hline & MSQ & $-0.461^{*}$ \\
\hline IWS & $-0.409^{*}$ & $-0.291^{*}$ \\
\hline Pay & $-0.189^{*}$ & $-0.453^{*}$ \\
\hline Autonomy & $-0.431^{*}$ & $-0.239^{*}$ \\
\hline Task requirement & $-0.243^{*}$ & $-0.304^{*}$ \\
\hline Organizational policy & $-0.239^{*}$ & $-0.320^{*}$ \\
\hline Professional status & $-0.267^{*}$ & 0.031 \\
\hline Interaction & -0.026 & \\
\hline ASQ & -- & $0.368^{*}$ \\
\hline JIT & $0.465^{*}$ & $0.405^{*}$ \\
ST & $0.386^{*}$ & $0.386^{*}$ \\
\hline
\end{tabular}

Note: IIWS, Index of Satisfaction scale; ASQ; Anxiety Stress Questionnaire; MOAQ: Michigan Organizational Assessment Questionnaire.

JIT, Job-induced tension; ST, Somatic tension; GFU, General fatigue and uneasiness.

$* \mathrm{p}=0.01 ; * \mathrm{p}=0.05$

\section{Relationships Between Nurses' Job Satisfaction and Socio-Demographic Variables}

Table 4 shows the results of the correlation tests between job satisfaction and socio-demographic data of the nurse respondents in this study. The nurses' age, post-registration experience and working experience in the hospital under study were significantly and positively correlated with the overall job satisfaction $(\mathrm{p}=0.01)$, as well as the subscales 'Pay' and 'Autonomy' ( $\mathrm{p}$ values $=0.05$ or 0.01 ). Their working experience was positively correlated with the 'Interaction' subscale ( $\mathrm{p}=0.05)$; their highest qualification was negatively correlated with the 'Organizational policy' subscale ( $\mathrm{p}=0.05)$; and their rank position was also positively correlated with the 'Pay' subscale ( $\mathrm{p}=0.01)$.

In terms of the nurses' satisfaction with 'Interaction', nurse-to-nurse interaction were positively correlated with age 
$(\mathrm{r}=0.258, \mathrm{p}=0.01)$, post-registration experience $(\mathrm{r}=0.206, \mathrm{p}=0.05)$ and working experience in the private hospital $(\mathrm{r}=0.214, \mathrm{p}=0.05)$.

Table 4. Correlations between nurses' job satisfaction and socio-demographic characteristics.

\begin{tabular}{|c|c|c|c|c|c|}
\hline & Age $+(n=124)$ & $\begin{array}{l}\text { Post-registration experience }+ \\
((n=135)\end{array}$ & $\begin{array}{c}\text { Working experience in the } \\
\text { hospital }+(n=135)\end{array}$ & $\begin{array}{l}\text { Highest qualification\# } \\
\qquad(\mathrm{n}=133)\end{array}$ & Rank\# $(n=139)$ \\
\hline IWS & $0.244 *$ & $0.195 *$ & $0.213^{*}$ & -0.156 & 0.118 \\
\hline Pay & $0.275^{*}$ & $0.227 *$ & $0.192 *$ & 0.073 & $0.307 *$ \\
\hline Autonomy & $0.249^{*}$ & $0.214^{*}$ & $0.256^{*}$ & -0.080 & 0.150 \\
\hline Task requirement & 0.056 & 0.074 & 0.083 & -0.108 & -0.001 \\
\hline Organizational policy & 0.063 & 0.014 & 0.021 & $-0.221 *$ & 0.001 \\
\hline Professional status & 0.068 & 0.026 & 0.011 & -0.040 & 0.034 \\
\hline Interaction & 0.164 & 0.140 & $0.191^{*}$ & -0.073 & 0.071 \\
\hline
\end{tabular}

+ Using Pearson's correlation test.

\# Using Spearman's correlation test.

* $\mathrm{p}=0.01$ level; * $\mathrm{p}=0.05$

\section{Comparisons of Job Satisfaction and Job Stress Between Subgroups}

As there were significant correlations found between nurse' job satisfaction and a few demographic variables (i.e., age, post-registration experience, working experience in the hospital, and highest qualification), subgroup analyses using ANOVA test were done in terms of these four demographic variables (see Table 5). There were significant differences in the mean scores of 'Pay' $(F=4.17, \mathrm{df}=130, \mathrm{p}=0.008)$ and 'Autonomy' $(\mathrm{F}=4.21, \mathrm{df}=130, \mathrm{p}=0.007)$ between three age subgroups (21-30, 31-40 and 41-60 years). The results of contrasts test indicated that the subgroup of aged 41-60 had significant higher satisfaction with their salary payment ('Pay') and autonomy than the other two subgroups (aged 21-30 and 31-40), with mean differences of $0.18(\mathrm{SE}=0.28, \mathrm{p}=0.005)$ and $0.13(\mathrm{SE}=0.12, \mathrm{p}=0.01)$, respectively. This aged 41-60 age subgroup also indicated higher satisfaction with their autonomy in clinical practice than the other two age subgroups (mean differences $=0.23$ and $0.15 ; \mathrm{SE}=0.24$ and $0.04, \mathrm{p}=0.005$ and 0.01 , respectively).

Table 5. Subgroup comparisons of levels of nurses' job satisfaction $(\mathrm{N}=139)$.

\begin{tabular}{|c|c|c|c|c|}
\hline & & \multicolumn{3}{|c|}{ IWS } \\
\hline & $\mathbf{n}$ & Pay & Autonomy & Organizational policy \\
\hline \multicolumn{5}{|l|}{ Age (years) } \\
\hline $21-30$ & 72 & $4.20(0.57)$ & $3.86(0.52)$ & $3.98(0.81)$ \\
\hline $31-40$ & 26 & $4.25(0.73)$ & $3.94(0.74)$ & $3.94(0.90)$ \\
\hline $41-60$ & 26 & $4.38(0.81)$ & $4.09(0.76)$ & $3.84(0.78)$ \\
\hline$F, d f, p$ values & & $4.17,130,0.008$ & $4.21,130,0.007$ & $1.89,130,0.10$ \\
\hline \multicolumn{5}{|l|}{ Post-registration experience (years) } \\
\hline$<5$ & 68 & $4.20(0.65)$ & $3.92(0.52)$ & $3.99(0.87)$ \\
\hline $5-10$ & 21 & $4.28(0.70)$ & $3.65(0.67)$ & $3.88(0.78)$ \\
\hline$>10$ & 46 & $4.33(0.87)$ & $4.13(0.79)$ & $3.89(0.91)$ \\
\hline$F, d f, p$ values & & $1.80,133,0.12$ & $4.15,133,0.018$ & $1.78,133,0.13$ \\
\hline \multicolumn{5}{|l|}{ Experience in private hospital (years) } \\
\hline$<5$ & 82 & $4.17(0.65)$ & $3.85(0.64)$ & $3.95(0.78)$ \\
\hline $5-10$ & 16 & $4.23(0.69)$ & $3.77(0.60)$ & $3.90(0.81)$ \\
\hline$>10$ & 37 & $4.53(0.80)$ & $4.24(0.66)$ & $3.86(0.85)$ \\
\hline$F, d f, p$ values & & $3.40,133,0.036$ & $5.42,132,0.005$ & $1.91,133,0.11$ \\
\hline \multicolumn{5}{|l|}{ Rank position } \\
\hline Enrolled nurse & 55 & $4.13(0.56)$ & $3.92(0.69)$ & $3.96(0.70)$ \\
\hline Registered nurse & 66 & $4.19(0.71)$ & $3.88(0.83)$ & $3.90(0.80)$ \\
\hline Senior registered nurse/ward manager & 18 & $5.23(0.31)$ & $3.87(0.76)$ & $3.87(0.81)$ \\
\hline$F, d f, p$ values & & $10.37,136,0.01$ & $2.10,136,0.12$ & $1.98,136,0.15$ \\
\hline \multicolumn{5}{|l|}{ Highest nursing qualification } \\
\hline Diploma & 30 & $4.73(0.89)$ & $3.95(0.89)$ & $3.97(0.54)$ \\
\hline Higher/Professional diploma & 28 & $4.69(0.88)$ & $3.87(0.81)$ & $3.74(0.80)$ \\
\hline Baccalaureate/Master & 75 & $4.73(0.51)$ & $3.92(0.79)$ & $3.40(0.72)$ \\
\hline
\end{tabular}




\begin{tabular}{|c|c|c|c|c|}
\hline & & \multicolumn{3}{|c|}{ IWS } \\
\cline { 2 - 5 } & $\mathbf{n}$ & Pay & Autonomy & Organizational policy \\
\hline$F, d f, p$ values & & $2.01,133,0.13$ & $1.97,133,0.15$ & $3.04,133,0.02$ \\
\hline
\end{tabular}

Note: IWS, Index of work satisfaction

In terms of post-registration experiences, the most experienced nurses ( $>10$ years) were significantly more satisfied with autonomy $(\mathrm{F}=4.15, \mathrm{df}=134, \mathrm{p}=0.018)$ and perceived less job induced tension $(\mathrm{F}=4.32, \mathrm{df}=134, \mathrm{p}=0.015)$ than the other two subgroups with 10 years experience or below (mean differences $=0.21$ and $0.48, \mathrm{SE}=0.25$ and $0.12, \mathrm{p}=0.03$ and 0.01 , respectively). Similarly for working experience in the private hospital, the most experienced nurses were more satisfied than the two less experienced subgroups in terms of 'Pay' $(\mathrm{F}=3.40, \mathrm{df}=134, \mathrm{p}=0.036)$ and 'Autonomy' $(\mathrm{F}=5.42, \mathrm{df}=134, \mathrm{p}=0.005)$. Their mean differences on 'Pay' were $0.44(\mathrm{SE}=0.23)$ and $0.30(\mathrm{SE}=0.11), \mathrm{p}=0.02$ and 0.04, respectively; whereas, their mean differences on 'Autonomy' were $0.31(\mathrm{SE}=0.02)$ and $0.39(\mathrm{SE}=0.01)$, respectively.

In addition, there was a significant difference on satisfaction with 'Pay' between job ranking $(\mathrm{F}=10.37, \mathrm{df}=138$, $\mathrm{p}=0.01$ ). Results of contrast tests test indicated that those enrolled nurses and registered nurses were significantly less satisfied with 'Pay' than the senior registered nurses and ward managers (mean differences $=1.1$ and $1.02, \mathrm{SE}=0.31$ and 0.40 , both $\mathrm{p}=0.01$, respectively).

Lastly, there was a significant difference on satisfaction for organizational policy in terms of levels of the highest nursing qualification $(\mathrm{F}=3.04, \mathrm{df}=132, \mathrm{p}=0.02)$. Nurses with bachelor or master degree education were significantly less satisfied with 'Organizational policy' than those with higher diploma or diploma education (mean difference $=0.57$ and $0.34, \mathrm{SE}=0.18$ and $0.12, \mathrm{p}=0.01$ and 0.04 , respectively).

Interestingly, it was also found that the nurses with less post-registration nursing experience $(\mathrm{F}=4.32, \mathrm{df}=133$, $\mathrm{p}=0.015)$ and lower job ranking $(\mathrm{F}=2.97, \mathrm{df}=137,0=0.034)$ reported higher levels of job stress (ASQ score).

\section{DISCUSSIONS}

\section{Pull Factor - Job Satisfaction}

Nurses in a Hong Kong private hospital in our study has indicated an overall moderate level of job satisfaction, with a mean IWS score of 3.81 ( $\mathrm{SD}=0.37$, possible range of $1-7)$. Comparing the results with similar study in Hong Kong by Lee [5] to investigate over 300 nurses' job satisfaction in two public hospitals. The level of job satisfaction in private hospital was higher than those in the public hospitals with a mean score of 3.46 and standard deviation of about 0.8. [5]. However, when compared with the findings of recent western studies, nurses' job satisfaction in the USA [45], Australia, [46] and Canada [47] were even higher than this Hong Kong study and all of them had a mean score of IWS above 4.0. The finding indicated that nurses in the western countries had more positive attitude towards their working environment which may be due to the small nurse-patient ratios in most clinical units and better professional development, autonomy and interdisciplinary collaboration occurred in overseas countries such as the U.S.A. and England $[45,48]$.

This study revealed that professional status and autonomy have been ranked as the two most satisfactory components of nurses' job satisfaction. This finding is in line with the reports of both local and western literature [5, 45, 49]. It might be explained by the fact that nursing profession is a high value career job [4], needing a high degree of clinical decision-making, regulation and independence, as well as inter-dependence among healthcare team members over the field of work [50].

Furthermore, it was identified that salary payment is the second most satisfactory component in this study. This finding is inconsistent with previous research studies. For example, salary was ranked as the fourth in Lee's study [5] and was rated as the least satisfactory in the USA [45], Ireland [48] and Australia [50]. One possible explanation of this inconsistency is that the salaries in Hong Kong private hospitals are higher than that working in local public hospitals and even those in overseas hospitals. Regarding the report of lower satisfaction on salary in western countries, there is a possibility that the daily expenditure and tax payment in those countries are higher than those Hong Kong. Therefore, nurses in other developed countries generally have a higher expected salary to compensate the work in shifting hours, night duties and high taxation for social welfare and security.

As a number of research suggested that the satisfaction for interaction was significant in improving staff retention, it is surprising and important to note that the mean score on 'Interaction' subscale in this study was found to be the 
second-lowest among the six job satisfaction components [51]. Other studies also argued that interaction between staff and staff and between staff and patient, was a satisfactory job component $[5,45,49]$. The low mean score on the subscale reflects that communication with and support from the healthcare teammates and physicians are insufficient in this hospital. However, it is understandable that the studied hospital uses primary nursing system instead of team nursing system in ward for patient care. Hence, nurses have to work independently with relatively low interaction between nursing staffs. Therefore, the nursing system may be one main contributing factor reducing the overall job satisfactory of the participants in this study. Shader et al. [51] also pointed out that peer and within-profession interactions and collaborations could be very useful and influential to improve nursing staff's job morale and satisfaction, hence improving staff retention.

Task requirement is an area where changes are needed as nurses have the lowest job satisfaction with task requirements among six job satisfaction components in this study. It may be the result of the highly demanded responsibility and heavy workload within limited time schedule. Similar findings were also reported by Molinari et al. [52], Cowin [49] and Lee [5].

In this study, nurses with higher education level tended to have lower satisfaction with organization policy. This result is consistent with the previous studies of Blegan [53], Chan et al. [28] and Lee [5], which indicated well-educated nurses had higher expectations towards their job and working condition, and less satisfactory with current quality of care. For this reason, they reported that they were less likely to stay in the current job if they perceived the looking environment could not be found satisfactory or favorable to their work and continuous development in nursing [4].

Consistent with other studies [4, 51, 54], nurses' job satisfaction was found to be highly negatively correlated with job stress and intention to quit. With reference to another study ( $\mathrm{Lu}$ et al., 2005), the factors that have negative influence on job satisfaction included heavy workload, shift duty and poor interpersonal relationship. Since some of these factors were also identified as the source of job related stress [32], it is hypothesized that job stress and heavy workload might contribute to low job satisfaction among nurses whereas, poor interpersonal relationship and interaction between nurses themselves and other healthcare professionals would eventually attenuate the situation, and hence increase their intention to quit. Such inter-relationships between these factors influence nurses' retention should be investigated in future research.

Moreover, nurses' job satisfaction of the study is strongly and positively correlated with a few demographic characteristics, including nurses' age, years of experience and working experience in the hospital. Younger in age and less working experience might be closely associated with poorer adjustment and cooperation at working conditions, less rewarding working experience and empowerment among nurses' counterparts (i.e. those senior nurses) $[5,7]$.

\section{Job Stress and Job Satisfaction}

The study was also designed to identify the relationship between job stress and job satisfaction. In our study, the findings indicated that the level of job stress is moderate. The mean score of IWS is significantly and negatively correlated with the total score of ASQ. The result is similar and coherent with the previous findings that job satisfaction was one of the strongest factors associated with stress $[2,55]$. Among the three job stress components in ASQ, jobrelated tension is ranked the highest and somatic tension the second; both were strong predictors for overall job satisfaction, which was consistent to another study of health professionals in public hospitals conducted by Leung et al. [2]. However, the nurses in our study perceived and reported a higher level of stress than those working in local public hospitals. Since work is often the major source of stress in nurses' lives, work overload and inadequate workforce in the studied hospital may be the major causes of a higher job stress [43].

In hospitals, nurse leaders and managers reported lower level of stress similar to the nurses in this study because they had better control of their time and tasks than nurses with a lower ranking or grades [2].

Job-induced tension in the less experienced nurses was found higher than those experienced nurses because less experienced nurses might have the first-line duty and responsibility to provide good quality of bedside care for their patients [2]. With less clinical experiences obtained, inadequate frontline staffs available [43] and poor supervision and support from the senior staff [56], the young and inexperienced nurses would be prone to experience a higher level of work stress in their practices requiring independent and important clinical, decision-making for their patients in needs.

While the job satisfaction and job stress were in moderate levels among the nurses in this study, the actual turnover rate of them over 6 months afterwards was relatively low (2.72). The moderate intention to leave among the nurses might be counteracted by other unmeasured possible factors, such as management style, generational diversity among 
staff and personal needs. Considering the fact that over half of the participants were young, single females, this professional job might have fulfilled their needs of job security and income stability. It is noted that professional status and autonomy were rated as the most satisfactory components; these nurses may be willing to maintain their jobs and endure the stress due to the sense of achievement they gained from work. In addition, in another study, Spear et al. [57] found that role clarity had a positive association with job satisfaction and a negative association with stress. Since the IWS has a limitation in measuring nurses' satisfaction on six domains, other significant domains, such as their perceived role clarity, satisfaction on management style and daily workload, have not been included. Hence, our results might not have reflected the overall job satisfaction level. There is a possibility that the nurses of our study had a positive attitude towards other factors missing in this study.

\section{Implications}

This was the first study to identify level of nurses' job satisfaction, stress and their related factors in a regional medium-sized private hospital. The findings have provided alerts for hospital administrators to improve current clinical working situation among nurses, which should be considered in order to increase job satisfaction (pull factor) while decreasing job stress (push factor), which in turn helps in maintaining nurses' retention and reducing challenge of nursing shortages in healthcare services. Regarding to the intention to quit, a change in management strategies such as becoming ore empowered and nurturing culture for professional development, might be able to improve the issues related to interaction and task requirements, as well as professional nursing status, pay (salary), and autonomy in workplace environment Recommendations for hospital administrative staff to improve job satisfaction includes the nurses managers could treat all nursing staff fairly, listening to the staff's concerns, identifying their working and even life problems at early stage, maintaining good working relationships with staff, especially the junior ones, and concerning their welfare, benefits and even health conditions. Hospital institutions should consider introducing training in stress management and coping skills, social activities and exercises among nurses regularly, encourage rapport and support from senior staff and peers to cope with complex and demanding working stress and relationships. Furthermore, nurse managers should create an open communication and consultation system among physicians, nurses and other healthcare staff to encourage their interaction and collaborations in work, so that workgroup cohesion, a team spirit and trust could be strengthened. Hence, this may help in promoting the quality of patient care with good interdisciplinary collaboration.

For long-term job satisfaction, the administrators should spend more time in collecting feedback regarding current organization policy to maintain nurses' level of job satisfaction. Establishing recognition program can promote compliments and acknowledgments of nurses' contributions to the patient care and working hospital. This can then enhance the sense of work engagement and thus job satisfaction among nurses. Further, top management team should review and modify the existing occupational stress management policy. For example, reducing administrative tasks and workload, providing sufficient mentoring or supervision, recruiting sufficient nurses to meet the needs for high demands of patient care with adequate nursing manpower, so as to relieve nurses' job related stress. Last but not least, career advancement is considered as a way to improve nurses' professional status, pay and autonomy in the workplace. Nursing administrators are suggested to encourage nurses to specialize in a specific area of clinical practice, which provide opportunities for acquiring new skills, gaining greater responsibility with higher job autonomy and granting potential for promotion to increase their job satisfaction and stability.

\section{Limitations}

There were several limitations in this study. The study design was cross-sectional and the sample was convenience sample that was drawn from a single private hospital, which may limit the power and generalization of the study. Further research can be conducted by employing more diverse, and larger sized samples from different private hospitals or even public to increase generalizability of the findings. Longitudinal prospective study can also be considered to examine the predictors of job satisfaction and/or actual turnover rate of the nurses in the studied hospital. Nevertheless, the actual turnover rate of nurses is better examined at least one year after the completion of the questionnaire which may be more realistic and indicative to the impact of job satisfaction and better understanding about the predictive effect of their intention to quit overtime. Whereas the six-month period of actual turnover used in this study may only be reflecting the behavior or actions of the nurses who were in very high levels of stress and/or very low levels of job satisfaction in the study. 


\section{CONCLUSION}

The study investigated the relationships between nurses' job satisfaction, job stress, intention to quit and their demographic characteristics. Overall, nurses in this private hospital had moderate levels of job stress, intention to quit and job satisfaction. There was a negative relationship between job stress and job satisfaction, and between intention to quit and job satisfaction. Besides, this study concluded that nurses with more working experiences in hospital were more satisfied with their job in terms of salary and autonomy in clinical practices, than nurses with less working experiences. They also reported having more interaction with other nurses and/or physicians and lower level of job related stress. Regarding satisfaction on organization policy, nurses with bachelor or master degree education demonstrated having a lower level of satisfaction than nurses with lower nursing qualification.

Aiming at reducing the cost of recruiting and training new staff in the healthcare system, the administrators of private hospitals are encouraged to develop strategic measures to enhance job satisfaction, and to reduce job stress on the intention to quit. Future research on nurses' job satisfaction in diverse samples in public and private hospitals and/or community settings, as well as predictive factors influencing its level of nurses' retention or turnover is necessary.

\section{CONFLICT OF INTEREST}

The authors confirm that this article contains no conflict of interest.

\section{ACKNOWLEDGEMENTS}

Declared None.

\section{REFERENCES}

[1] Willem A, Buelens M, De Jonghe I. Impact of organizational structure on nurses' job satisfaction: a questionnaire survey. Int J Nurs Stud 2007; 44(6): 1011-20 [http://dx.doi.org/10.1016/j.ijnurstu.2006.03.013] [PMID: 16709414]

[2] Leung SK, Spurgeon PC, Cheung HK. Job satisfaction and stress among ward-based and community-based psychiatric nurses. Hong Kong J Psychiatry 2007; 17(2): 45-54.

[3] Coomber B, Barriball KL. Impact of job satisfaction components on intent to leave and turnover for hospital-based nurses: a review of the research literature. Int J Nurs Stud 2007; 44(2): 297-314. [http://dx.doi.org/10.1016/j.ijnurstu.2006.02.004] [PMID: 16631760]

[4] Siu OL. Predictors of job satisfaction and absenteeism in two samples of Hong Kong nurses. J Adv Nurs 2002; 40(2): 218-29. [http://dx.doi.org/10.1046/j.1365-2648.2002.02364.x] [PMID: 12366652]

[5] Fung-kam L. Job satisfaction and autonomy of Hong Kong registered nurses. J Adv Nurs 1998; 27(2): $355-63$. [http://dx.doi.org/10.1046/j.1365-2648.1998.00527.x] [PMID: 9515647]

[6] Yamashita M, Takase M, Wakabayshi C, Kuroda K, Owatari N. Work satisfaction of Japanese public health nurses: assessing validity and reliability of a scale. Nurs Health Sci 2009; 11(4): 417-21. [http://dx.doi.org/10.1111/j.1442-2018.2009.00464.x] [PMID: 19909451]

[7] Ning S, Zhong H, Libo W, Qiujie L. The impact of nurse empowerment on job satisfaction. J Adv Nurs 2009; 65(12): 2642-8. [http://dx.doi.org/10.1111/j.1365-2648.2009.05133.x] [PMID: 19941547]

[8] Education Bureau. Annual Report 2010 Hong Kong SAR. China: Education Bureau 2010.

[9] Chan MF, Leong SM, Luk AL, Yeung SM, Van IK. Exploring the profiles of nurses' job satisfaction in Macau: results of a cluster analysis. J Clin Nurs 2010; 19(3-4): 470-8.

[http://dx.doi.org/10.1111/j.1365-2702.2009.02902.x] [PMID: 19886871]

[10] Stamps PL. Nurses and work satisfaction: an index for measurement. $2^{\text {nd }}$ ed. Chicago: Health Administration Press 1997.

[11] Utriainen K, Kyngäs H. Hospital nurses’ job satisfaction: a literature review. J Nurs Manag 2009; 17(8): $1002-10$. [http://dx.doi.org/10.1111/j.1365-2834.2009.01028.x] [PMID: 19941574]

[12] Flanagan NA. Testing the relationship between job stress and satisfaction in correctional nurses. Nurs Res 2006; 55(5): $316-27$. [http://dx.doi.org/10.1097/00006199-200609000-00004] [PMID: 16980832]

[13] Leggat SG, Bartram T, Casimir G, Stanton P. Nurse perceptions of the quality of patient care: Confirming the importance of empowerment and job satisfaction. Health Care Manage Rev 2010; 35(4): 355-64. [http://dx.doi.org/10.1097/HMR.0b013e3181e4ec55] [PMID: 20844360]

[14] Lu H, While AE, Barriball KL. Job satisfaction among nurses: a literature review. Int J Nurs Stud 2005; 42(2): 211-27. [http://dx.doi.org/10.1016/j.ijnurstu.2004.09.003] [PMID: 15680619]

[15] Abu Raddaha AH, Alasad J, Albikawi ZF, et al. Jordanian nurses' job satisfaction and intention to quit. Leadersh Health Serv 2012; 25(3): 
216-31

[http://dx.doi.org/10.1108/17511871211247651]

[16] Stichler JF. Healthy, healthful, and healing environments: a nursing imperative. Crit Care Nurs Q 2009; 32(3): 176-88. [http://dx.doi.org/10.1097/CNQ.0b013e3181ab9149] [PMID: 19542969]

[17] Brewer CS, Kovner CT. Work satisfaction among staff nurses in acute care hospitals. In: Dickson GL, Flynn L, Eds. Nursing Policy Research: Turning Evidence-based Research into Health Policy. New York: Springer Publishing Co. 2009; pp. $127-42$.

[18] Kovner CT, Brewer CS, Greene W, Fairchild S. Understanding new registered nurses' intent to stay at their jobs. Nurs Econ 2009; 27(2): 81-98. [PMID: 19492772]

[19] Williams A. Job stress, job satisfaction, and intent to leave employment among maternal-child health nurses, Master of Science in Nursing Dissertation. Huntington, West Virginia: Marshall University 2003. Available from: http://www.marshall.edu/etd/masters/ williamsannette-2003-msn.pdf

[20] Gruss VA. Relation of work empowerment to job satisfaction and absenteeism among dementia-care certified nursing assistants in long-term facilities [unpublished dissertation]. Chicago: Rush University 2002.

[21] Brewer CS, Kovner CT, Greene W, Cheng Y. Predictors of RNs' intent to work and work decisions 1 year later in a U.S. national sample. Int J Nurs Stud 2009; 46(7): 940-56. [http://dx.doi.org/10.1016/j.ijnurstu.2008.02.003] [PMID: 18377910]

[22] Cavanagh SJ, Coffin DA. Staff turnover among hospital nurses. J Adv Nurs 1992; 17(11): 1369-76. [http://dx.doi.org/10.1111/j.1365-2648.1992.tb01861.x] [PMID: 1430645]

[23] Kalliath T, Morris R. Job satisfaction among nurses: a predictor of burnout levels. J Nurs Adm 2002; 32 (12): 648-54. [http://dx.doi.org/10.1097/00005110-200212000-00010] [PMID: 12483086]

[24] Ferlise P, Baggot D. Improving staff nurse satisfaction and nurse turnover: use of a closed-unit staffing model. J Nurs Adm 2009; 39(7-8): 318-20. [http://dx.doi.org/10.1097/NNA.0b013e3181ae967f] [PMID: 19641428]

[25] McNeese-Smith DK. A content analysis of staff nurse descriptions of job satisfaction and dissatisfaction. J Adv Nurs 1999; 29(6): 1332-41 [http://dx.doi.org/10.1046/j.1365-2648.1999.01018.x] [PMID: 10354227]

[26] Wang Y. Job satisfaction of nurses in hospital. Chinese Nursing 2002; 37(8): 593-4. [In Chinese].

[27] Adams A, Bond S. Hospital nurses’ job satisfaction, individual and organizational characteristics. J Adv Nurs 2000; $32(3)$ : 536-43. [http://dx.doi.org/10.1046/j.1365-2648.2000.01513.x] [PMID: 11012794]

[28] Chan MF, Leong SM, Luk AL, Yeung SM, Van IK. Exploring the profiles of nurses' job satisfaction in Macau: results of a cluster analysis. J Clin Nurs 2010; 19(3-4): 470-8.

[http://dx.doi.org/10.1111/j.1365-2702.2009.02902.x] [PMID: 19886871]

[29] Bratt MM, Broome M, Kelber S, Lostocco L. Influence of stress and nursing leadership on job satisfaction of pediatric intensive care unit nurses. Am J Crit Care 2000; 9(5): 307-17. [PMID: 10976354]

[30] Hu J, Liu H. Job satisfaction among nurses in China. Home Health Care Manage Pract 2004; 17(1): 9-13. [http://dx.doi.org/10.1177/1084822304268154]

[31] Tzeng HM. The influence of nurses' working motivation and job satisfaction on intention to quit: an empirical investigation in Taiwan. Int $\mathbf{J}$ Nurs Stud 2002; 39(8): 867-78. [http://dx.doi.org/10.1016/S0020-7489(02)00027-5] [PMID: 12379304]

[32] McVicar A. Workplace stress in nursing: a literature review. J Adv Nurs 2003; 44(6): 633-42. [http://dx.doi.org/10.1046/j.0309-2402.2003.02853.x] [PMID: 14651686]

[33] McGilton KS, Hall LM, Wodchis WP, Petroz U. Supervisory support, job stress, and job satisfaction among long-term care nursing staff. J Nurs Adm 2007; 37(7-8): 366-72. [http://dx.doi.org/10.1097/01.NNA.0000285115.60689.4b] [PMID: 17939468]

[34] Lee H, Hwang S, Kim J, Daly B. Predictors of life satisfaction of Korean nurses. J Adv Nurs 2004; 48(6): 632-41. [http://dx.doi.org/10.1111/j.1365-2648.2004.03251.x] [PMID: 15548254]

[35] Cook JD, Hepworth SJ, Wall TD, Warr PB. The experience of work: a compendium and review of 249 measures and their use. London: Academic Press Inc. 1981.

[36] Hemingway MA, Smith CS. Organisational climate and occupational stressors as predictors of withdrawal behaviours and injuries in nurses. J Occupat Nurs 1999; 72(3): 285-99.

[37] Hek G, Judd M, Moule P. Making sense of research An introduction for health and social care practitioners. $2^{\text {nd }}$ ed. London: Sage 2002

[38] Thomas RM. Blending qualitative and quantitative research methods in theses and dissertations. California: Corwin Press 2003.

[39] Wang MQ, Fitzhugh E, Westerfield RC. Determining sample size for simple-random surveys. Health Values 1995; 19 : 53-6. 
[40] Cohen J. A power primer. Psychol Bull 1992; 112(1): 155-9. [http://dx.doi.org/10.1037/0033-2909.112.1.155] [PMID: 19565683]

[41] Stamps PL, Piedmonte EB. Nurses and work satisfaction: an index for measurement. Chicago: Health Administration Press 1986.

[42] House M, Rizzo A. Role conflict and ambiguity as critical variables in a model of organizational behavior. Organ Behav Hum Perform 1972; 7: 467-505. [http://dx.doi.org/10.1016/0030-5073(72)90030-X]

[43] Callaghan P, Tak-Ying SA, Wyatt PA. Factors related to stress and coping among Chinese nurses in Hong Kong. J Adv Nurs 2000; 31(6): 1518-27. [http://dx.doi.org/10.1046/j.1365-2648.2000.01434.x] [PMID: 10849166]

[44] Cammann C, Fichman M, Jenkins GD, Klesh J. The michigan organizational assessment questionnaire. In: Seashore SE, Lawler PH, Mirvis PH, Cammann C, Eds. Assessing organizational change: A guide to methods, measures, and practices. New York: Wiley-Interscience 1983; pp. 71-138.

[45] Amos MA, Hu J, Herrick CA. The impact of team building on communication and job satisfaction of nursing staff. J Nurses Staff Dev 2005; 21(1): 10-6 [http://dx.doi.org/10.1097/00124645-200501000-00003] [PMID: 15731637]

[46] Takase M, Kershaw E, Burt L. Nurse-environment misfit and nursing practice. J Adv Nurs 2001; 35(6): 819-26. [http://dx.doi.org/10.1046/j.1365-2648.2001.01933.x] [PMID: 11555029]

[47] Best MF, Thurston NE. Measuring nurse job satisfaction. J Nurs Adm 2004; 34(6): 283-90. [http://dx.doi.org/10.1097/00005110-200406000-00007] [PMID: 15190223]

[48] Curtis EA. Job satisfaction: a survey of nurses in the Republic of Ireland. Int Nurs Rev 2007; 54(1): 92-9. [http://dx.doi.org/10.1111/j.1466-7657.2007.00507.x] [PMID: 17305963]

[49] Cowin L. The effects of nurses' job satisfaction on retention: an Australian perspective. J Nurs Adm 2002; 32(5): $283-91$. [http://dx.doi.org/10.1097/00005110-200205000-00008] [PMID: 12021569]

[50] Traynor M, Boland M, Buus N. Autonomy, evidence and intuition: nurses and decision-making. J Adv Nurs 2010; 66(7): 1584-91. [http://dx.doi.org/10.1111/j.1365-2648.2010.05317.x] [PMID: 20497271]

[51] Shader K, Broome ME, Broome CD, West ME, Nash M. Factors influencing satisfaction and anticipated turnover for nurses in an academic medical center. J Nurs Adm 2001; 31(4): 210-6. [http://dx.doi.org/10.1097/00005110-200104000-00010] [PMID: 11324334]

[52] Molinari DL, Monserud M. Rural nurse cultural self-efficacy and job satisfaction. J Transcult Nurs 2009; 20(2): 211-8 [http://dx.doi.org/10.1177/1043659608330350] [PMID: 19171695]

[53] Blegen MA. Nurses' job satisfaction: a meta-analysis of related variables. Nurs Res 1993; 42(1): 36-41. [PMID: 8424066]

[54] Lu KY, Lin PL, Wu CM, Hsieh YL, Chang YY. The relationships among turnover intentions, professional commitment, and job satisfaction of hospital nurses. J Prof Nurs 2002; 18(4): 214-9. [http://dx.doi.org/10.1053/jpnu.2002.127573] [PMID: 12244540]

[55] Blegen MA. Nurses' job satisfaction: a meta-analysis of related variables. Nurs Res 1993; 42(1): 36-41. [PMID: 8424066]

[56] McGilton KS, Hall LM, Wodchis WP, Petroz U. Supervisory support, job stress, and job satisfaction among long-term care nursing staff. J Nurs Adm 2007; 37(7-8): 366-72. [http://dx.doi.org/10.1097/01.NNA.0000285115.60689.4b] [PMID: 17939468]

[57] Spear J, Wood L, Chawla S, Devis A, Nelson J. Job satisfaction and burnout in mental health services for older people. Australas Psychiatry 2004; 12(1): 58-61. [http://dx.doi.org/10.1046/j.1039-8562.2003.02061.x] [PMID: 15715741]

(C) Chien and Yick; Licensee Bentham Open

This is an open access article licensed under the terms of the Creative Commons Attribution-Non-Commercial 4.0 International Public License (CC BY-NC 4.0) (https://creativecommons.org/licenses/by-nc/4.0/legalcode), which permits unrestricted, non-commercial use, distribution and reproduction in any medium, provided the work is properly cited. 